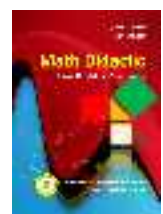

MATH DIDACTIC: JURNAL PENDIDIKAN MATEMATIKA

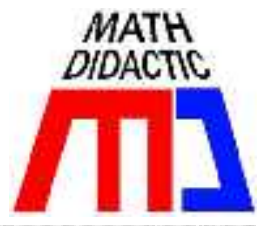
KEEFEKTIFAN PEMBELAJARAN MATEMATIKA MODEL PBL BERBASIS ETNOMATEMATIKA MOTIF KAIN SASIRANGAN TERHADAP KEMAMPUAN PEMECAHAN MASALAH SISWA

\title{
THE EFFECTIVENESS OF MATHEMATICAL LEARNING PBL MODEL BASED ON ETHNOMATHEMATIC SASIRANGAN MOTIVES OF TOWARDS STUDENT SOLVING ABILITY
}

Rahmi Hidayati, Ratna Restapaty

STIKES Borneo Lestari

rahmihidayati.pmatc@gmail.com, ratnarestapaty@gmail.com

\begin{abstract}
Abstrak: Salah satu model pembelajaran matematika yang dapat diterapkan untuk mengasah kemampuan pemecahan masalah adalah problem based learning (PBL). Dalam hal ini kemampuan pemecahan masalah dapat dikolaborasikan dengan budaya lokal yang ada. Tujuan dalam penelitian ini adalah untuk mengetahui keefektifan model PBL berbasis etnomatematika motif kain sasirangan terhadap kemampuan pemecahan masalah siswa yang dilihat dari ketuntasan individual (KKM) dan ketuntasan klasikal. Populasi pada penelitian ini siswa kelas VII SMP Muhammadiyah Banjarbaru tahun ajaran 2018/2019. Sampel penelitian diambil dengan teknik cluster random sampling, dimana VII E sebagai kelas eksperimen dan VII F sebagai kelas kontrol. Pengumpulan data dengan metode dokumentasi, observasi dan tes. Uji hipotesis yang digunakan adalah uji rata-rata dan uji proporsi. Hasil penelitian menunjukkan bahwa model PBL berbasis etnomatematika motif kain sasirangan terhadap efektivitas kemampuan pemecahan masalah peserta didik, ditunjukkan dengan kemampuan pemecahan masalah peserta didik mencapai ketuntasan individual di atas KKM dan ketuntasan klasikal 75\%. Dapat dilihat dari ratarata kemampuan pemecahan masalah peserta didik kelas eksperimen adalah 83,33 dan kelas kontrol adalah 73 . Ketuntasan klasikal untuk kelas eksperimen sebesar $77 \%$ dan kelas kontrol $40 \%$.
\end{abstract}

Kata Kunci: keefektifan, problem based learning, etnomatematika, kemampuan pemecahan masalah, motif kain sasirangan

\begin{abstract}
One model of mathematics learning that can be applied to hone problem solving skills is problem based learning (PBL). In this case the problem-solving ability can be collaborated with the existing local culture. The purpose of this study was to determine the effectiveness of ethnomathematics-based PBL models of Sasirangan motifs on students' problem solving abilities as seen from individual completeness (KKM) and classical completeness. The population in this study was VII grade students of SMP Muhammadiyah Banjarbaru in the 2018/2019 school year. The research sample was taken by cluster random sampling technique, where VII E was the experimental class and VII F was the control class. Data collection by the method of documentation, observation and tests. The hypothesis test used is the average test and the proportion test. The results showed that the PBL model based on ethnomathematics of Sasirangan motifs on the effectiveness of students 'problem solving abilities, was shown by the students' problem solving abilities reaching individual completeness above KKM and classical completeness of $75 \%$. Can be seen from the average problem solving ability of students in the experimental class is 83.33 and the control class is 73. Classical completeness for the experimental class was $77 \%$ and the control class was $40 \%$.
\end{abstract}

Keywords: effectiveness, problem based learning, ethnomathematics, problem solving ability, sasirangan fabric motives

Cara Sitasi: Hidayati, R., \& Restapaty, R. (2019). Keefektifan pembelajaran matematika model PBL berbasis etnomatematika motif kain sasirangan terhadap kemampuan pemecahan masalah siswa. Math Didactic: Jurnal Pendidikan Matematika, 5(2), 210-218. https://doi.org/10.33654/math.v5i2.674 
Dalam pembelajaran matematika terdapat beberapa kemampuan yang harus dimiliki oleh peserta didik. Di dalam memecahkan masalah peserta didik harus mengikuti proses untuk memecahkan masalah. Karatas \& Baki (2013) mengemukakan bahwa "Problem solving is recognized as an important life skill involving a range of processes including analyzing, interpreting, reasoning, predicting, evaluating and reflecting". National Council of Teacher Mathematics (NCTM, 2000) menyatakan bahwa "Problem solving is an integral part of all mathematics learning”. pemecahan masalah merupakan hal yang penting dari suatu pembelajaran matematika.

Salah satu model pembelajaran yang dapat membentuk kemampuan pemecahan masalah siswa adalah model Problem Based Learning. Model Problem Based Learning (PBL) menurut Barrows, (dalam Barrett, 2010) PBL adalah "The learning that results from the process of working towards the understanding of a resolution of a problem. The problem is encountered first in the learning process". Dari pendapat tersebut menyatakan bahwa PBL adalah suatu pembelajaran yang dihasilkan dari proses bekerja menuju pemahaman masalah, dimana masalah diberikan pada awal proses pembelajaran sehingga siswa yang selalu aktif, guru hanya sebagai fasilitator karena guru memberikan suatu permasalahan untuk siswa. Pada model pembelajaran ini, peserta didik dikelompokkan dalam kelompok kecil kemudian saling bekerja sama untuk menyelesaikan lembar kerja yang dibagikan pada setiap kelompok.

Berdasarkan penelitian yang dilakukan oleh Gunantara (2014) menyatakan bahwa model pembelajaran
PBL dapat meningkatkan kemampuan pemecahan masalah pada pembelajaran matematika. Menurut Khoiri, dkk. (2013) dalam PBL masalah yang diajukan oleh guru adalah permasalahan dunia nyata dan menarik, sehingga siswa lebih dilatih untuk memecahkan masalah yang membutuhkan pemikiran kreatif.

Kemampuan memecahkan masalah yang harus dimiliki oleh peserta didik meliputi kemampuan memahami masalah, merancang model matematika, menyelesaikan model dan menafsirkan solusi yang diperoleh BNSP (2006). Berdasarkan prinsip-prinsip dan standar matematika sekolah dari National Council of Teacher Mathematics NCTM (2000) menyatakan bahwa "Problem solving is an integral part of all mathematics learning”. Ini berarti pemecahan masalah merupakan hal yang penting dari suatu pembelajaran matematika.

Pada penelitian ini kemampuan pemecahan masalah diukur melalui kemampuan dalam menyelesaikan masalah dengan menggunakan langkah-langkah Polya (1973), ada empat langkah yang harus dilakukan untuk memecahkan suatu masalah. Adapun keempat langkah tersebut adalah sebagai berikut (1) Understanding the problem (memahami masalah), (2) Devising a plan (merencanakan pemecahan masalah), (3) Carrying out the plan (melaksanakan pemecahan masalah), dan (4) Looking back (melihat kembali hasil yang diperoleh).

Etnomatematika merupakan pembelajaran matematika yang mengaitkan ke dalam kearifan lokal budaya. Hal ini sesuai dengan pendapat yang dikemukakan oleh Sirate (2012) menyatakan bahwa pengajaran matematika bagi setiap orang 
seharusnya disesuaikan dengan budayanya. Banyak kearifan lokal (budaya) yang dapat digunakan dalam pembelajaran matematika salah satu kearifan lokal yang ada di Kalimantan salah satunya adalah kain sasirangan. Menurut Winarsih (2015) kain sasirangan merupakan kerajinan yang unik dan memiliki beberapa unsur nilai seperti nilai keyakinan, nilai budaya, dan nilai ekonomis. Sedangkan Ganie (2014) menyatakan klasifikasi penamaan kain sasirangan berdasarkan pada motif gambar dan warna motif. Kain sasirangan memiliki berbagai motif ada yang disebut dengan gigi haruan, kambang, hiris gagatas dan masih banyak lagi. Dari motif - motif didominasi garis - garis berganda baik dua atau tiga garis. Dengan etnomatematika siswa dapat mengkaji konsep-konsep matematika ke dalam praktek budaya dan membantu dalam pemecahan masalah.

Hal ini sesuai dengan pendapat Shirley dalam Hartoyo (2012) berpandangan bahwa sekarang ini bidang etnomatematika, yaitu matematika yang tumbuh dan berkembang dalam masyarakat dan sesuai dengan kebudayaan setempat, dapat digunakan sebagai pusat proses pembelajaran dan metode pengajaran, walaupun masih relatif baru dalam dunia pendidikan. Agar pembelajaran matematika menjadi lebih menarik minat siswa maka pembelajaran matematika menggunakan permasalahan yang terdapat di lingkungan sekitar khususnya dengan mengaitkannya dengan budaya lokal yang ada di Kalimantan Selatan salah satunya motif kain Sasirangan.

Berdasarkan hasil observasi yang dilakukan di SMP Muhammadiyah Banjarbaru, Kriteria Ketuntasan Minimal (KKM) SMP Muhammadiyah Banjarbaru adalah 78 dan ketuntasan klasikal sebesar $75 \%$. Sedangkan hasil wawancara yang dilakukan dengan guru mata pelajaran matematika di tempat tersebut mengakui bahwa, selama ini proses pembelajaran yang dilakukan masih teacher centered dimana pembelajaran berlangsung lebih didominasi guru yang dikenal dengan konvensional. Hal ini dikarenakan kekhawatiran guru terhadap materi yang diberikan tidak tersampaikan dengan baik penyebabnya antara peserta didik terdapat siswa yang memiliki kebutuhan khusus. Hal yang sama juga diakui oleh peserta didik yang menyatakan bahwa selama ini pembelajaran matematika guru lebih dominan.

Penelitian ini bertujuan untuk mengetahui tingkat keefektifan pembelajaran matematika model PBL dengan berbasis etnomatematika motif kain sasirangan terhadap kemampuan pemecahan masalah, dan juga untuk mengetahui tingkat ketuntasan secara individual dengan nilai KKM 78 dan ketuntasan klasikal $75 \%$.

\section{Metode Penelitian}

Penelitian ini dilakukan pada bulan Maret - April 2019 di kelas VII E dan VII F di SMP Muhammadiyah Banjarbaru. Populasi pada penelitian ini adalah siswa kelas VII SMP Muhammadiyah Banjarbaru tahun ajaran 2018/2019. Kelas VII terbagi menjadi 6 kelas yaitu kelas VII A - VII F. Pengambilan Sampel menggunakan teknik cluster random sampling yaitu secara acak dari 6 kelas terpilih 2 kelas yaitu kelas VII E sebagai kelas eksperimen dan kelas VII F sebagai kelas kontrol. 
Teknik pengumpulan data yang digunakan dalam penelitian ini adalah berupa dokumentasi untuk memperoleh nilai ujian tahun ajaran 2017/2018, tes kemampuan pemecahan masalah berupa tes uraian yang sebelumnya dilakukan uji coba. Jenis penelitian yang dilaksanakan adalah penelitian kuantitatif. Dengan menggunakan quasi experimental design. Dalam desain posttestonly control terdapat dua kelompok, kelompok pertama yang diberi perlakuan disebut kelompok eksperimen dan kelompok kedua yang tidak diberi perlakuan disebut kelompok kontrol Sugiyono (2012).

Tahap awal yang dilakukan adalah melakukan uji normalitas dan homogenitas dari nilai ulangan matematika siswa tahun ajaran sebelumnya. Dilanjutkan dengan melakukan uji coba instrumen penelitian untuk mengetahui kriteria validitas, reliabilitas, tingkat kesukaran, dan daya pembeda.

Validasi butir soal menggunakan korelasi product moment dengan rumus sebagai berikut.

$$
=\frac{T_{X}}{\sqrt{\left\{N \sum X^{2}-\left(\sum X\right)^{2}\right\}\left\{N \sum Y^{2}-\left(\sum Y\right)^{2}\right\}}}
$$

dimana,

$T_{X}=$ koefisien korelasi

$\mathrm{N}$ = besarnya sampel/banyaknya subjek

$\sum X=$ jumlah skor tiap butir soal

$\sum Y=$ jumlah skor total

$\sum X^{2}=$ jumlah kuadrat skor tiap butir soal

$\sum Y^{2}=$ jumlah kuadrat skor total

Item butir soal dinyatakan valid jika $r_{x}>r_{t_{1}} \quad$ dengan taraf signifikan yang digunakan $5 \%$.

Untuk reliabilitas instrumen dianalisis dengan menggunakan rumus Alpha sebagai berikut.

$$
r_{1}=\left(\frac{n}{n-1}\right)\left(1-\frac{\sum \sigma_{1}^{2}}{\sigma_{1}^{2}}\right)
$$

Dengan rumus variansi:

$$
\begin{gathered}
\sigma_{i}^{2}=\left(\frac{\sum X^{2}-\frac{\left(\sum X\right)^{2}}{N}}{N}\right) \\
\sigma_{t}^{2}=\frac{\sum Y^{2}-\frac{(Y)^{2}}{N}}{N}
\end{gathered}
$$

Item butir soal dinyatakan valid jika $T_{\text {nit }} \quad>T_{t i}$ dengan taraf signifikan yang digunakan $5 \%$.

Untuk menghitung taraf kesukaran digunakan rumus yaitu:

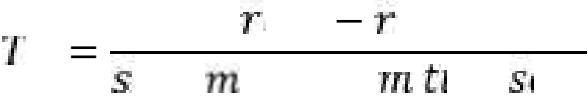

$$
\begin{aligned}
& \text { dengan, } \\
& r \quad-r
\end{aligned}
$$

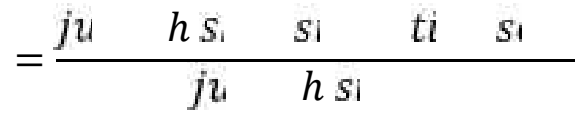

Arifin (2012)

Dengan kriteria taraf kesukaran sebagai berikut:

Tabel 1. Taraf kesukaran

\begin{tabular}{lc}
\hline Interval & Kategori taraf kesukaran \\
\hline $\mathbf{0 , 0 0}-\mathbf{0 , 3 0}$ & Sukar \\
$\mathbf{0 , 3 1}-\mathbf{0 , 7 0}$ & Sedang \\
$\mathbf{0 , 7 1}-\mathbf{1 , 0 0}$ & Mudah \\
\hline Arifin $(2012)$ &
\end{tabular}

Untuk menghitung daya pembeda soal rumus yang digunakan yaitu :

dimana,

$$
\nu=\frac{\bar{X}_{K}-\bar{X}_{K}}{S m}
$$

$D$ = Daya Pembeda

$\bar{X}_{K}=$ Rata-rata nilai kelompok atas

$\bar{X}_{K}=$ Rata-rata nilai kelompok bawah Arifin (2012)

Tahap selanjutnya melaksanakan pembelajaran pada kelas eksperimen dengan 
model problem based learning berbasis etnomatematika sedangkan untuk kelas kontrol pembelajaran menggunakan model konvensional. Setelah proses pembelajaran selesai maka dilakukan post-test untuk mengukur kemampuan pemecahan masalah baik kelas eksperimen maupun kelas kontrol dimana post-test tersebut sudah dilakukan uji coba terlebih dahulu.. Post-test yang diberikan berupa tes uraian sebanyak 5 soal pemecahan masalah. Hasil tes tersebut digunakan sebagai data untuk melihat tingkat ketuntasan secara individual dengan KKM 78 dan ketuntasan secara klasikal $75 \%$ serta membandingkan kemampuan pemecahan masalah dari perlakuan yang berbeda.

\section{Hasil Penelitian dan Pembahasan}

\section{Hasil}

Analisis awal yang dilakukan adalah uji normalitas untuk mengetahui apakah suatu data berasal dari populasi yang berdistribusi normal atau tidak. Data yang diambil dari nilai ujian sebelumnya dengan materi yang sama. Pengujian normalitas yang dilakukan dengan menggunakan uji Kolmogorov-Smirnov dilanjutkan dengan melakukan uji homogenitas (uji kesamaan Variansi). Berikut hasil uji normalitas dan uji homogenitas yang dapat dilihat pada tabel 2 berikut.

Tabel 2. Hasil Uji Normalitas \& Homogenitas

\begin{tabular}{lrrrr}
\hline & \multicolumn{2}{l}{$\begin{array}{l}\text { Kolmogorov- } \\
\text { Smirnov }\end{array}$} & \multicolumn{2}{c}{$\begin{array}{l}\text { Homogeneity of } \\
\text { variances }\end{array}$} \\
\hline & Statistic & Sig & Sig & \\
\hline $\begin{array}{l}\text { Nilai_ } \\
\text { Ujian }\end{array}$ & .061 & .080 & & .551 \\
\hline
\end{tabular}

Tes uraian kemampuan pemecahan masalah berbasis etnomatematika motif kain sasirangan terlebih dahulu dilakukan uji coba untuk mengetahui validitas butir soal, reliabilitas soal, taraf kesukaran dan daya pembeda. Berikut hasil validitas, reliabilitas, taraf kesukaran dan daya pembeda dari 5 soal tes uraian:

\section{Tabel 3. Hasil Validitas Butir soal}

\begin{tabular}{|c|c|c|c|c|c|}
\hline No & \multicolumn{3}{|c|}{ Validitas } & \multicolumn{2}{|c|}{ Reliabel } \\
\hline Soal & $\begin{array}{c}\mathbf{r} \\
\text { hitung }\end{array}$ & $\begin{array}{c}r \\
\text { tabel }\end{array}$ & Ket & $\mathbf{r}_{11}$ & Ket \\
\hline 1 & 0,885 & 0.388 & Valid & 0,828 & Reliabel \\
\hline 2 & 0,795 & & Valid & & Reliabel \\
\hline 3 & 0,789 & & Valid & & Reliabel \\
\hline 4 & 0,887 & & Valid & & Reliabel \\
\hline 5 & 0,638 & & Valid & & Reliabel \\
\hline
\end{tabular}

Tabel 4. Hasil Daya Pembeda

\begin{tabular}{lll}
\hline $\begin{array}{l}\text { No } \\
\text { Soal }\end{array}$ & $\begin{array}{l}\text { Nilai Daya } \\
\text { Pembeda }\end{array}$ & \multicolumn{1}{c}{ Ket } \\
\hline $\mathbf{1}$ & 0,27 & Cukup \\
$\mathbf{2}$ & 0,44 & Sangat Baik \\
$\mathbf{3}$ & 0,59 & Sangat Baik \\
$\mathbf{4}$ & 0,45 & Sangat Baik \\
$\mathbf{5}$ & 0,26 & Cukup \\
\hline
\end{tabular}

Tabel 5. Hasil Tingkat Kesukaran

\begin{tabular}{|c|c|c|}
\hline $\begin{array}{l}\text { No } \\
\text { Soal }\end{array}$ & $\begin{array}{l}\text { Nilai Tingkat } \\
\text { Kesukaran }\end{array}$ & Kategori \\
\hline 1 & 0,7 & Sedang \\
\hline 2 & 0,62 & Sedang \\
\hline 3 & 0,58 & Sedang \\
\hline 4 & 0,31 & Sedang \\
\hline 5 & 0,67 & Sedang \\
\hline
\end{tabular}

Setelah diperoleh validitas butir soal, reliabel, daya pembeda dan taraf kesukaran maka kedua kelas yang dijadikan sampel 
dilakukan proses pembelajaran dengan perlakuan yang berbeda. Kelas eksperimen diberikan perlakuan dengan model PBL berbasis etnomatematika motif kain sasirangan dan kelas kontrol dengan pembelajaran konvensional. Setelah diberikan perlakuan yang berbeda, kemudian dilanjutkan dengan tes kemampuan pemecahan masalah.

Hasil post test terhadap kemampuan pemecahan masalah disimpulkan sebagai berikut :

Tabel 6. Simpulan Hasil Post Tes Terhadap Kemampuan Pemecahan Masalah

\begin{tabular}{ccc}
\hline Kelas & Eksperimen & Kontrol \\
\hline Rata-rata $(\overline{\boldsymbol{x}})$ & 83,33 & 73 \\
Nilai Tertinggi & 98,75 & 87,5 \\
Nilai Terendah & 70 & 60 \\
Standar Dev. & 7.45 & 7.81 \\
$\mathrm{n}$ & 26 & 25 \\
\hline
\end{tabular}

Hasil hitung uji ketuntasan individual diperoleh $t_{\text {nit }} \quad 3,99>t_{t_{1}} \quad 2,06$ yang menunjukkan bahwa rata-rata nilai kemampuan pemecahan masalah peserta didik dengan model PBL berbasis etnomatematika motif kain sasirangan secara ketuntasan individual lebih baik dari KKM.

Untuk ketuntasan klasikal diperoleh 20 orang siswa dari 26 siswa di kelas eksperimen tuntas secara klasikal dengan nilai KKM 78 yaitu sebesar $77 \%$ dari keseluruhan.

\section{Pembahasan}

Data awal yang dilakukan untuk uji kenormalan didapat bahwa nilai sig sebesar 0,080 dimana nilai sig $0,080>0,05$ dimana data menunjukkan berdistribusi normal. Untuk kesamaan variansi (homogenitas) diperoleh sebesar 0,551 dimana nilai sig 0,551>0,05 yang menunjukkan bahwa data memiliki variansi yang sama. Setelah uji normalitas dan homogenitas terpenuhi dilanjutkan dengan uji kesamaan rata-rata untuk melihat kemampuan awal yang dimiliki dari dua kelas perlakuan. Dari hasil uji kesamaan rata-rata diperoleh nilai sig 0,653>0,05 dan $t_{\text {nit }}=-1,848$. Untuk tingkat taraf signifikan $5 \%$, diperoleh $t_{t_{1}}=1,674$ artinya tidak terdapat perbedaan kemampuan awal antara kedua kelas.

Berdasarkan perhitungan dengan taraf signifikan $5 \%, \mathrm{n}=26 r_{t_{1}} \quad p r \quad m$

yang diperoleh adalah 0,388 dimana $\tau_{\text {nit }}>$ $r_{t_{1}} \quad$ menunjukkan hasil validitas butir soal sebanyak 5 soal uraian kemampuan Kontriplecahan masalah berbasis etnomatematika h3otif kain sasirangan semuanya adalah valid. 7 Ur mtuk melihat instrumen dapat dipercaya maka dilakukan uji reliabilitas. Berdasarkan Thastl uji coba diperoleh $T_{\text {nit }}=0,828$ đengan $r_{t_{1}} p \quad m \quad=0,388$ dimana $r_{\text {nit }}>r_{t_{1}}$ menunjukkan soal pemecahan masalah reliable. Sehingga untuk tingkat kevalidan dan reliable butir soal sudah terpenuhi.

$$
\text { Daya pembeda merupakan }
$$
kemampuan suatu soal membedakan antara peserta didik yang berkemampuan tinggi dengan peserta didik yang berkemampuan rendah. Dari hasil daya pembeda yang dilakukan menunjukkan bahwa dari 5 soal kemampuan pemecahan masalah berbasis etnomatematika motif kain sasirangan 3 soal dengan kriteria sangat baik yaitu butir soal nomor 2, 3, dan 4. Dua soal kriteria cukup yaitu butir soal nomor 1 dan 5 .

Tes uraian kemampuan pemecahan masalah juga dilakukan tingkat kesukarannya. Jika tes yang dibuat dengan tingkat kesukaran mudah maka soal tersebut tidak layak untuk digunakan sehingga dianjurkan untuk diperbaiki. Hal ini sesuai menurut pendapat Arifin (2012). Soal kemampuan pemecahan 
masalah yang terdapat pada penelitian ini dari hasil uji coba diperoleh 4 dari 5 soal berada di kategori sedang yaitu pada nomor 1,2, 3 dan 5 sedangkan satu soal berada di kategori sukar yaitu pada soal nomor 4 .

Hasil tes kemampuan pemecahan masalah setelah diberikan perlakuan data yang diperoleh dilakukan uji kenormalan dan kehomogenan yang dilanjutkan dengan melihat ketuntasan secara individual dengan one sample t test dan klasikal (uji proporsi satu pihak). Dari hasil ketuntasan individual diperoleh $t_{\text {nit }} \quad 3,99>t_{t_{1}} \quad 2,06$ yang menunjukkan bahwa rata-rata nilai kemampuan pemecahan masalah peserta didik dengan model PBL berbasis etnomatematika motif kain sasirangan secara ketuntasan individual lebih baik dari KKM.

Dari hasil ketuntasan klasikal diperoleh $Z_{\text {nit }} \quad 1,15>Z_{t_{1}} \quad 0,67$ yang menunjukkan bahwa persentase ketuntasan hasil kemampuan pemecahan masalah peserta didik dengan model PBL berbasis etnomatematika motif kain sasirangan secara ketuntasan klasikal yang mendapat nilai $\geq 78$ mencapai lebih dari $75 \%$.

Untuk mengetahui kemampuan pemecahan masalah dari dua kelas perlakuan menggunakan uji independent sample test diperoleh nilai sig 0,002 <0,005 yang artinya kemampuan pemecahan masalah dengan menggunakan model pembelajaran PBL berbasis etnomatematika motif kain sasirangan lebih baik dari pada menggunakan model pembelajaran konvensional. Rata-rata kemampuan pemecahan masalah kelas eksperimen adalah 83,33 dan kelas kontrol 73. Hal ini sesuai dengan penelitian yang dilakukan oleh Yumiati (2013) yang menganalisis kemampuan pemecahan masalah peserta didik melalui model PBL SMPN 9 Pamulang. Penelitian tersebut menyatakan bahwa pembelajaran PBL lebih baik dari pada pembelajaran biasa dalam meningkatkan kemampuan pemecahan masalah matematis peserta didik SMPN 9 Pamulang serta materi matematika menjadi lebih dipahami oleh peserta didik pada saat pembelajaran. Sirate (2012) yang menyimpulkan bahwa penerapan etnomatematika sebagai sarana untuk memotivasi, menstimulasi peserta didik, dapat mengatasi kejenuhan dan kesulitan dalam belajar matematika.

\section{Simpulan dan Saran}

\section{Simpulan}

Berdasarkan hasil penelitian mengenai keefektifan pembelajaran matematika model PBL berbasis etnomatematika motif kain sasirangan pada sub materi persegi panjang dan persegi terhadap kemampuan pemecahan masalah peserta didik kelas VII semester 2 SMP Muhammadiyah Banjarbaru, maka dapat diambil kesimpulan bahwa Pembelajaran matematika model PBL berbasis etnomatematika motif kain sasirangan terhadap kemampuan pemecahan masalah peserta didik adalah efektif dilihat dari: (1) Kemampuan pemecahan masalah pada sub materi persegi panjang dan persegi dengan model PBL berbasis etnomatematika motif kain sasirangan pada siswa SMP Muhammadiyah kelas VII E secara individual telah tuntas dari KKM dengan rata-rata 83,33 dan ketuntasan klasikal yang lebih dari $75 \%$ yaitu $77 \%$ peserta didik SMP kelas VII E mendapat nilai lebih dari KKM. Kemampuan pemecahan masalah peserta didik SMP kelas VII pada sub materi persegi panjang dan persegi dengan menggunakan model PBL berbasis etnomatematika motif 
kain sasirangan lebih efektif dari kelas dengan menggunakan pembelajaran konvensional.

\section{Saran}

Berdasarkan kesimpulan yang diperoleh, maka dapat menjadi masukan bagi pihak-pihak terkait seperti sekolah, guru, serta pemerhati pendidikan agar mendorong terciptanya pembelajaran yang mengangkat budaya lokal khususnya motif kain sasirangan. Saran dari penelitian ini adalah: sebagai berikut. (1) perlu diperhatikan dalam pemilihan soal-soal pemecahan masalah kontekstual dalam menerapkan model PBL berbasis etnomatematika motif kain sasirangan. (2) perlu diperhatikan kembali untuk persiapan perangkat pembelajaran, pengelolaan waktu, dan pengelolaan kelas pada saat pelaksanaan pembelajaran dengan model PBL berbasis etnomatematika motif kain sasirangan. (3) Penerapan pembelajaran matematika dengan model PBL berbasis etnomatematika khususnya motif kain sasirangan sebaiknya disesuaikan terlebih dahulu dengan materi yang akan diajarkan, agar mudah untuk mengaitkan soal pemecahan masalah dengan budaya lokal setempat. (4) Bagi peneliti lain bisa menggunakan model pembelajaran yang lain dengan mengangkat budaya lokal yang dimiliki.

\section{Daftar Pustaka}

Arifin, Z. (2012). Evaluasi pembelajaran. Bandung: Remaja Rosdakarya. https://doi.org/979-692-956-2

Barrett, T. \& Cashman, D. 2010. A Practitioners' Guide to Enquiry and Problem-based Learning. Dublin: UCD Teaching and Learning.
Ganie, T. N. 2014. Sasirangan Kain Khas Tanah Banjar. Kalimantan Selatan: Tuas Media.

Gd. Gunantara, Md. Surjana, P. N. R. (2014). Penerapan Model Pembelajaran Problem Based Learning Untuk Meningkatkan Pemecahan Masalah Matematika Siswa Kelas V. Quality. https://doi.org/10.1073/pnas.0703993104

Hartoyo, A. (2012). Eksplorasi Etnomatematika pada Budaya Masyarakat Dayak Perbatasan IndonesiaMalaysia Kabupaten Sanggau Kalbar. Jurnal Penelitian Pendidikan.

Karatas, I., \& Baki, A. (2013). The effect of learning environments based on problem solving on students' achievements of problem solving. International Electronic Journal of Elementary Education.

Khoiri, W., Rochmad, \& Cahyono, A. N. (2013). Problem Based Learning Berbantuan Multimedia dalam Pembelajaran Matematika untuk Meningkatkan Kemampuan Berpikir Kreatif. Unnes Journal of Mathematics Education.

BNSP (2006). Standar Isi Untuk Satuan Pendidikan Dasar dan Menengah, Peraturan Menteri Pendidikan Nasional.

NCTM. (2000). Principles and Standards for School Mathematics. In School Science and Mathematics.

Polya, G. 1973. How to Solve It ( $2^{\text {nd }}$ ed.). New Jersey: Princeton University Press

Richardo, R. 2016. Peran Ethnomatematika dalam Penerapan Pembelajaran Matematika pada Kurikulum 2013. Universitas Alma Ata Yogyakarta 7(2), 118-125. 
Seman, S. 2007. Sasirangan Kain Khas Banjar. Kalimantan Selatan: Lembaga Pengkajian dan Pelestarian Budaya Banjar.

Sirate, F. S. (2012). Implementasi Etnomatematika Dalam Pembelajaran Matematika Pada Jenjang Sekolah Dasar. Lentera Pendidikan.

Sugiyono. (2012). Metode Penelitian Kuantitatif, Kualitatif dan R \& D.Bandung:Alfabeta. Metode Penelitian Kuantitatif, Kualitatif Dan $R \quad \&$ D.Bandung:Alfabeta. https://doi.org/10.1017/CBO9781107415 324.004

Winarsih, T. 2015. Kain Sasirangan dan Asalusul Batik di Indonesia: CV.Sabdo Pinilih.

Yumiati. 2013. Penerapan Model Pembelajaran Berbasis Masalah dalam Meningkatkan Kemampuan Pemecahan Masalah Matematis siswa SMPN 9 Pamulang. Jurnal Pendidikan Vol.1. Program Studi Pendidikan Matematika STKIP Bandung. 